\title{
The Grammar of Interpersonal Meaning in Wole Soyinka's A Play of Giants
}

\author{
Innocent Sourou Koutchadé
}

Senior Lecturer, Applied Linguistics, Department of English Studies, Faculty of Arts and Humanities (F.L.A.S.H) University of Abomey-Calavi (UAC) / BENIN; Email: koutchade2@yahoo.fr

\section{Doi:10.5901/mjss.2016.v7n5p299}

\begin{abstract}
The aim of this article is to use the analytic and linguistic tools drawn from Systemic Functional Linguistics (SFL) to inquire into the language of Wole Soyinka's play entitled: A Play of Giants. In order to stress how the protagonists interact with one another, the paper focuses on the study of interpersonal meaning. The method of analysis is that of sampling. The data, thus, includes two excerpts selected and analyzed through the linguistic features of mood, modality and adjuncts. The findings reveal that the two texts display various mood-types, mainly declarative, interrogative and imperative mood, as well as features of modality, including modulation and modalisation, which are combined with adjunct features to contribute to the realization of interpersonal function and to decode the tenor of discourse in the play. The work concludes that interpersonal meaning is an important theory as it has made it easy to decode the language and style of the writer and account for how the writer has satirized the characters of the play to address some of the political issues confronting contemporary Africa.
\end{abstract}

Keywords: Systemic Functional Linguistics (SFL), interpersonal meaning, mood, modality, adjuncts, tenor.

\section{Introduction}

One important way of analyzing literary texts successfully is to use linguistic methods. This is probably one of the major goals set up by stylistics which is commonly viewed as the study of style. As observed by Simpson (2004), doing stylistics enriches people's ways of thinking about language and, exploring language offers a substantial purchase on people's understanding of literary texts. For Ngara (1982), in order to arrive at a satisfactory understanding of literature, the reader must have an understanding of language, its function and operation. In this respect, the reader must have to recourse to linguistics for a full understanding of the phenomenon of language. Thus, to provide a relevant investigation of some aspects of the message conveyed by Wole Soyinka, this research paper carries out a stylistic analysis of this writer's play entitled A Play of Giants through the approach devised by Systemic Functional Linguists.

As a matter of fact, Wole Soyinka is one of the most prolific West African literary scholars. He has produced various literary works such as prose, poetry, plays, essays, etc. and has been more concerned not only with issues related to his culture and society, but also with those affecting his country in particular and Africa in general. As a matter of fact, A Play of Giants focuses on themes around the subject of power. In this play, Soyinka describes the authoritarian and dictatorial regimes which have arisen in Africa in the days following the independence. Through the selection of two excerpts from the play, this study uses a theory about systems of meaning and relationship between language and social context to analyze Wole Soyinka's play. First, the theoretical approach related to mood, modality and tenor of discourse is accounted for and, second, a clause-to-clause analysis is provided so that the main linguistic features are studied to make it easy to find out some instances of meanings being made in the play under study.

\section{Theoretical Foundation: Interpersonal Meaning}

SFL views language as a social- semiotic system, i.e., a meaning-making process which includes experiential, interpersonal and textual meanings. According to Simpson (2004), the interpersonal meaning is about how we orientate, shape and measure our utterances as discourse. Bloor \& Bloor (2004) emphasize this assertion as follows: "language is used to enable us to participate in communicative acts with other people, to take on roles and to express and understand feelings, attitudes" (p.11). This is why Halliday \& Mattiessen (2014, p.135) contend that an 'act' of speaking is something that might more appropriately be called an inter-act: it is an exchange, in which giving implies receiving and demanding implies giving in response. Actually, the interpersonal meaning is realized through the mood patterns of the grammar and modality (Eggins, 1994). According to Eggins (1994), the mood structure of a clause has to do with the organization of the functional constituents of that clause. As a matter of fact, each mood-type corresponds to each function. In that regard, Eggins (1994/2004) summarizes the different mood-types with their related speech functions in table 1 below: 
Table1: Speech function and mood-types (adapted from Eggins,1994 / 2004)

\begin{tabular}{l|l}
\hline Speech function & Mood-types of clause \\
\hline Statement & Declarative mood \\
\hline Question & Interrogative mood \\
\hline Command & Imperative mood \\
\hline Offer & modulated interrogative mood \\
\hline Answer/achnowledgements & Elliptical declarative mood \\
\hline Accept/compliance & Minor clause \\
\hline
\end{tabular}

As pointed out by Bloor \& Bloor (2004, p. 46), in SFL, a clause is divided into two parts: the Mood and the Residue. The Mood is made up of Subject and Finite whereas the Residue includes the Predicator, Complement and Adjuncts. The second component of the realization of interpersonal meaning is modality. Halliday (1985a) defines it as the area of meaning that lies between yes and no- the intermediate ground between positive and negative polarity" (p.335). It is the expression of attitude and judgments. That is why Amoussou (2015) contends that "modality functions to indicate some aspects of the writer's/speaker's/ narrator's attitudes to the subject matter, or his/her comment on its trueness, relevance, reliability". On his part Fowler (1986) quoted by Koutchadé (2015) argues that " modality is the grammar of explicit comment, the means by which people express their degree of commitment to the truth of the propositions they utter, and their views on the desiderability or otherwise of the state of affairs referred to" (p.131). Modality includes modalization, i.e, the expression of speaker's judgment about certainty, likelihood, frequency, and operates through finite modal operators (can, may, must, etc.) or mood adjuncts (I think, l'm certain, I think, it is probable, etc. and modulation i.e., the expression of obligation and inclination through the finite verbal operators (must, will, shall, have to, etc).

Actually, the interpersonal meaning is the realization of the tenor of discourse (Hasan ,1985/1989; Eggins 1994). The tenor of discourse is a component of context of situation, i.e., the social environment in which meanings are being exchanged Halliday\& Hasan (1985/1989). It refers to who is taking part, to the nature of the participants, their status and roles. Put another way, it relates to the role relation of power and solidarity between the interactants: speaker/listener, addresser/addressee, writer or narrator/ reader or the writer/ speaker's attitude to the subject matter, etc. (Amoussou, 2015). Eggins (1994/2004) views the tenor of discourse as the social role played by interactants and points out those three dimensions for tenor which are "power", "contact" and "affective involvement". As a matter of fact, the way people interact with one another always determines whether they have equal or unequal power, frequent or infrequent power and high or low affective involvement.

\section{The Analysis}

In order to facilitate the analysis of linguistic features related to mood, modalities and adjuncts, the sampling method used has consisted in selecting some excerpts from the play under study. To that purpose, two excerpts (henceforth text1 and text2) have been selected and analyzed. As a matter of fact, the first excerpt is a conversation between the "life president" KAMINI and his minister, CHAIRMAN who has been sent to negotiate for the president a loan of hundred million dollars from the World Bank. As for the second text, it mainly focuses on a conversation between KAMINI and AMBASSADOR about some eminent and well educated members of the government who have secretly decided to run away. The two texts have been selected because they mainly focus on the same theme. The analysis is carried out quantitatively and qualitatively.

\subsection{Statistical analysis of text 1}

In this section, various mood-types, modality and adjuncts have been identified. The result of this task is displayed in the appendix. As a matter of fact, a need to carry out a thorough analysis of these linguistic features used in the speech of each character of the selected extracts has prompted us to count, tabulate and display their number and related percentages, as identified in the first extract, in table 2 below: 
Table 2: Statistics of mood, modality and adjunct-types in text 1

\begin{tabular}{|c|c|c|c|c|c|}
\hline \multirow[b]{2}{*}{ Mood Types } & \multicolumn{4}{|c|}{ Interactants (Frequency/ Percentage) } & \multirow[b]{2}{*}{ Total } \\
\hline & KAMINI & CHAIRMAN & GUDRUM & KASCO & \\
\hline Full declaratives & $63(58.33 \%)$ & $38(35.18 \%)$ & $06(05.55 \%)$ & $01(0.92 \%)$ & 108 \\
\hline Elliptical declaratives & $00(00 \%)$ & $00(00 \%)$ & $00(00 \%)$ & $00(00 \%)$ & 00 \\
\hline Polar interrogatives & $06(100 \%)$ & $00(00.00 \%)$ & $00(00 \%)$ & $00(00 \%)$ & 06 \\
\hline Full Wh-interrogatives & $15(100 \%)$ & $00(00 \%)$ & $00(00 \%)$ & $00(00 \%)$ & 15 \\
\hline Elliptical wh-interrogative & $02(100 \%)$ & $00(00 \%)$ & $00(00 \%)$ & $00(00 \%)$ & 02 \\
\hline Exclamatives & $00(00 \%)$ & $00(00 \%)$ & $00(00 \%)$ & $00(00 \%)$ & 00 \\
\hline Imperatives & $13(100 \%)$ & $00(00 \%)$ & $00(00 \%)$ & $00(00 \%)$ & 13 \\
\hline Modulated interrogatives & $00(00 \%)$ & $01(100 \%)$ & $00(00 \%)$ & $00(00 \%)$ & 01 \\
\hline Minor clauses & $03(75 \%)$ & $01(25 . \%)$ & $00(00 \%)$ & $00(00 \%)$ & 03 \\
\hline Abandoned & $00(00 \%)$ & $04(100 \%)$ & $00(00 \%)$ & $00(00 \%)$ & 04 \\
\hline Total/ percentages of mood per interactant & $10268 \%$ & $4127.33 \%$ & $0604 \%$ & $010.66 \%$ & $150100 \%$ \\
\hline djunct types & KAMINI & CHAIRMAN & GUDRUM & KASCO & Total \\
\hline Circumstantial & $44(75.86 \%)$ & $12(20.69 \%)$ & $02(03.44 \%)$ & $00(00 \%)$ & 58 \\
\hline Mood & $09(50 \%)$ & $08(44.44 \%)$ & $01(05.56 \%)$ & $00(00 \%)$ & 18 \\
\hline Polarity & $01(100 \%)$ & $00(00 \%)$ & $00(00 \%)$ & $00(00 \%)$ & 01 \\
\hline Vocative & $01(04.35 \%)$ & $19(82.61 \%)$ & $02(08.69 \%)$ & $01(04.35 \%)$ & 23 \\
\hline Comment & $00(00 \%)$ & $00(00 \%)$ & $00(00 \%)$ & $00(00 \%)$ & 00 \\
\hline Conjunctive & $21(61.76 \%)$ & $12(35.39 \%)$ & $01(02.89 \%)$ & $00(00 \%)$ & 34 \\
\hline Continuity & $01(50 \%)$ & $01(50 \%)$ & $00(00 \%)$ & $00(00 \%)$ & 02 \\
\hline Totals/ percentages of modality per interactan & $77(56.65 \%)$ & $52(38.35 \%)$ & $06(4.41 \%)$ & $01(0.73 \%)$ & 136 \\
\hline Modality-types & KAMINI & CHAIRMAN & GUDRUM & KASCO & Total \\
\hline Modalisation & $05(66.66 \%)$ & $02(25 \%)$ & $01(12.5 \%)$ & $00(00 \%)$ & 08 \\
\hline Modulation & $00(00 \%)$ & $01(100 \%)$ & $00(00 \%)$ & $00(00 \%)$ & 01 \\
\hline Total and percentages per interactant & $05(55.55 \%)$ & $03(33.33 \%)$ & $01(11.11 \%)$ & $00(00 \%)$ & 09 \\
\hline
\end{tabular}

The above table summarizes the way mood-types, adjuncts and modalities are distributed in the text. As a matter of fact, the study of mood types illustrates that there are one hundred and fifty (150) clauses out of which one hundred and eight (108) display full declarative mood-types, distributed among the four interactants: KAMINI [63 (58.33\%)], CHAIRMAN: [38 (35.18\%)], GUDRUM: [06 (05.55\%)], KASCO: [01 (00.92\%)]. There are also some cases of incomplete clauses in declarative form. These four clauses are used by CHAIRMAN [04 (100\%)]. In addition, the text displays some instances of minor clauses, in declarative form, which are shared by KAMINI [03 (75\%)] and CHAIRMAN [01 (25\%)]. Consequently, it turns out that declarative mood overrides the other mood-types in the text. This suggests that the participants have mainly exchanged information. Moreover, the use of minor and abandoned clauses is suggestive of a dialogic mode which occurs in the text. Apart from declarative mood, interrogatives are used in this text. They are 21 in number, all of which are used by KAMINI and distributed as follows: fifteen (15) wh-interrogatives, (6) polar interrogatives, and two (2) elliptical interrogatives. This highlights the fact that president KAMINI requires more information through questions. Considering the exchange of goods and services, only thirteen (13) imperatives are uttered entirely by KAMINI. This implies that Kamini has power and authority over CHAIRMAN and other interactants.

Regarding the adjuncts, the table shows 58 circumstantial adjuncts. Their use is an indication that the writer has added adverbs or prepositional phrases to the clauses. Besides, these are experiential elements which specify manner, time, purpose, place, etc. (Eggins, 1994/2004) and are distributed among interactants as follows: KAMINI [44 (75.86\%)], CHAIRMAN [12 (20.69\%)] and GUDRUM [02 (03.44\%)]. Conjunctive adjuncts rank second and they are used to link clauses in a cohesive and coherent manner. Over the 21 conjunctive elements identified, KAMINI has used 21 (61.76\%), CHAIRMAN, 12 (35.39\%), and GUDRUM, 01(02.89\%). In addition, 23 vocative adjuncts have been identified. They are mainly used by CHAIRMAN [19 (82.61\%)]. The remaining ones are distributed among GUDRUM [02 (08.69\%)], KAMINI $[01(04.35 \%)]$ and KASCO [01 (04.35\%)]. This denotes the way interactants address one another and the relationships that exist between them.

Moreover, mood adjuncts rank third, expressing interpersonal meanings related to usuality and probability. They are 18 in total: KAMINI has used 09 (50\%), CHAIRMAN 08 (44.44\%) and GUDRUM 01(05.56\%). Moreover, only two continuity adjuncts are used and shared between KAMINI: [01 (50\%)] and CHAIRMAN: [01 (50\%)], whereas 01 polarity adjunct occurs in KAMINI's speech. As for comment adjuncts, there are non-existent. 
As far as modality is concerned, interactants have made use of it to express their attitudes and judgments regarding the subject matter of their talk. In fact, the statistical figures show 08 instances of modalizations distributed between KAMINI [05 (66.66\%)], CHAIRMAN [02 (25\%)] and GUDRUM [01 (8.33\%)] while only one (1) modulation is used standing for $7.69 \%$. This highest modalization attributed to KAMINI proves that he is in a position of power over the other interactants. Finally, it is important to point out that the passage is almost unmodulated. The only case occurs in CHAIRMAN's speech. The above statistical figures have provided relevant information about the distribution of mood, modality and adjuncts, all of which are components of mood patterns and interpersonal meaning. A need to assess the language of the writer through these linguistic features requires a further appreciation of each of them.

\subsection{Statistical analysis of text2}

Table 3: Statistics of mood-types, modality and adjuncts in text2

\begin{tabular}{|c|c|c|c|c|}
\hline \multirow{2}{*}{ Mood- types } & \multicolumn{3}{|c|}{ Interactants } & \multirow{2}{*}{ Totals } \\
\hline & KAMINI & AMBASSADOR & GUDRUM & \\
\hline Full declaratives & $65(62.5 \%)$ & $30(28.84 \%)$ & $09(08.65 \%)$ & 104 \\
\hline Elliptical declaratives & $00(00 \%)$ & $00(00 \%)$ & $00(00 \%)$ & 00 \\
\hline Polar interrogatives & $06(100 \%)$ & $00(00 \%)$ & $00(00 \%)$ & 06 \\
\hline Wh-interrogatives & $17(100 \%)$ & $00(00 \%)$ & $00(00 \%)$ & 17 \\
\hline Elliptical wh-interrogatives & $02(100 \%)$ & $00(00 \%)$ & $00(00 \%)$ & 02 \\
\hline Exclamatives & $01(100 \%)$ & $00(00 \%)$ & $00(00 \%)$ & 01 \\
\hline Imperatives & $10(100 \%)$ & $00(00 \%)$ & $00(00 \%)$ & 10 \\
\hline Modulated interrogatives & $00(00 \%)$ & $00(00 \%)$ & $00(00 \%)$ & 00 \\
\hline Minor clauses & $10(90.90 \%)$ & $01(09.09 \%)$ & $00(00 \%)$ & 11 \\
\hline Abandoned /incomplete clauses & $00(00 \%)$ & $06(100 \%)$ & $00(00 \%)$ & 06 \\
\hline Total percentages per interactant & $111(70.70 \%)$ & $37(23.56 \%)$ & $09(5.73 \%)$ & 157 \\
\hline Adjunct-types & KAMINI & AMBASSADOR & GUDRUM & Total \\
\hline Circumstantial & $36(63.15 \%)$ & $20(35.08 \%)$ & $01(1.75 \%)$ & $57(48.71 \%)$ \\
\hline Mood & $04(50 \%)$ & $02(25 \%)$ & $02(25 \%)$ & 08 \\
\hline Polarity & $00(00 \%)$ & $00(00 \%)$ & $00(00 \%)$ & 00 \\
\hline Vocative & $02(12.50 \%)$ & $11(68.75 \%)$ & $03(18.75 \%)$ & 16 \\
\hline Comment & $00(00 \%)$ & $00(00 \%)$ & $01(100 \%)$ & 01 \\
\hline Conjunctive & $26(76.47 \%)$ & $07(28.58 \%)$ & $01(2.94 \%)$ & 34 \\
\hline Continuity & $00(00 \%)$ & $01(100 \%)$ & $00(00 \%)$ & 01 \\
\hline Totals and percentages per interactant & $68(58.11 \%)$ & $41(35.04 \%)$ & $08(06.83 \%)$ & 117 \\
\hline Modality & KAMINI & AMBASSADOR & GUDRUM & Total \\
\hline Modalisations & 06 (54.54\%) & $03(27.27 \%)$ & $02(18.18 \%)$ & 11 \\
\hline Modulations & $01(16.66 \%)$ & $05(83.33 \%)$ & $00(00 \%)$ & 06 \\
\hline $\begin{array}{l}\text { Total and percentages per interactant } \\
\text {. }\end{array}$ & $07(41.17 \%)$ & $08(47.05 \%)$ & $02(11.76 \%)$ & 17 \\
\hline
\end{tabular}

As the above table exudes, one hundred and fifty-seven clauses have been identified in this extract. Out of this number, one hundred and four (104) are full declaratives. The distribution of these declaratives among participants shows that KAMINI ranks first with 65 clauses standing for $62.5 \%$ followed by AMBASSADOR with 30 clauses standing for (28.84\%) and finally GUDRUM: [09 (08.65\%)]. This text also displays some cases of interrogative clauses. As a matter of fact, we have identified 25 interrogative mood clauses in which there are $17 \mathrm{Wh}-, 06$ polar and 02 elliptical interrogatives. More importantly, these interrogatives are all used by KAMINI. The dominance of these full declaratives and the use of interrogatives imply that interactants are mainly concerned with making statements and giving information through sequences of questions- answers. More importantly, interrogative mood clauses are all produced by KAMINI. Moreover, there are ten (10) imperative clauses which are used by KAMINI. The presence of imperatives shows that apart from giving information, this text serves as a forum for interactants to exchange goods and services. Eventually, one can notice the use of minor and abandoned clauses in the text. In fact, there are 11 minor clauses shared by KAMINI [10 (90.90\%)] and AMBASSADOR [01(09.09\%)]. Minor clauses occur in AMBASSADOR's speech: [06 (100\%)]. The use of these minor and incomplete clauses is an evidence of the dialogic mode feature that the text displays.

As far as adjuncts are concerned, these three interactants have used 117 of different types. Among these adjuncttypes, circumstantial are the most predominant with a total of 57 . Out of these 57 adjuncts, KAMINI has used 36 
(63.15\%), AMBASSADOR: 20 (35.08\%) and GUDRUM: 01 (1.75\%). This is indicative of experiential elements of time, location, matter, cause, etc. added to the clauses (Eggins, 1994) to specify the circumstances, time, places, etc. related to the processes expressed in the clauses. The twenty-four (24) conjunctive adjuncts used are distributed among KAMINI [26(76.47\%)], AMBASSADOR [07 (28.58\%)], and GUDRUM [01 (2.94\%)]. They point out that connectors or linking words are used cohesively and coherently to tie up clauses.

Vocative adjuncts come third with a total of sixteen (16). The use of these elements by AMBASSADOR [11 (68.75\%)], GUDRUM [03(18.75\%)] and KAMINI [02 (12.50\%)] shows the interpersonal relationship that exist among these interactants. Apart from these adjunct-types, there are eight (08) mood adjuncts, which are also distributed among the participants of the text including KAMINI [04 (50\%)], AMBASSADOR [02 (25\%)], and GUDRUM [02 (25\%)]. The use of mood adjuncts means that expressions of probability, intensification, inclination, etc. are used in the texts. Finally, continuity adjuncts are almost non-existent in the text: [01 (100\%)] whereas polarity and comment adjuncts are totally non-existent.

Moreover, from the above table, one can notice the use of modality in the text. There are eleven (11) modalisations shared among the interactants as follows: KAMINI [06 (54.54\%)], AMBASSADOR [03 (27.27\%)], GUDRUM [02(18.18\%)]. Such a distribution reveals that these participants have expressed their attitudes and judgments which are more related to probability and judgments. Likewise, there are six (06) modulations in the text, which are distributed among KAMINI [01 (16.66\%)] and AMBASSADOR [05(83.33\%)]. This means that the two participants have expressed obligations and inclination by giving goods and services. The following section makes it easy to elaborate on the mood, modalities and adjuncts analyses in this extract.

\section{Discussion and Conclusion}

As said earlier, declarative mood is mostly predominant in text 1 . Some of their clauses of occurrence are $(6,7,11,12$, $14,15,16,19,20,22,23,29,36,37,38,39,44,45,46,55,56,57,64,65,66,90,91,100,106,107,108,109,112,113$, $114,115,132,133,134,135)$. These clauses are mainly used by KAMINI and are meant to convey information. Actually, CHAIRMAN has come to KAMINI to inform him that the World Bank has refused to grant Bugara the loan of two hundred million dollars. This has irritated KAMINI and the need to receive more information has prompted him to use both polar and Wh-interrogative mood clauses. As a matter of fact, polar interrogatives occur in $(8,21,126,127,129,133)$ whereas Wh-interrogatives, whether elliptical or full interrogatives are expressed in clauses $(2,5,17,18,40,67,68,74,75,78,80$, $111,116,117)$, to name only these. KAMINI has put clarification questions to CHAIRMAN and the latter cannot but attempt to answer questions in declarative forms to provide KAMINI with convincing information. Actually, the writer has used features of elliptical interrogatives to "create a rethorical interactive context" (Eggins, 1994, p.314). In that respect, the predominance of Wh- over polar interrogatives shows clearly that Kamini does not want to admit that his request for Ioan has been objected. To show his disagreement, he uses imperative mood in $(25,26,33,34,53,54,92,97,98,102$, 103) to order CHAIRMAN to go back to the World Bank and not only agree to any conditions on which they insisted but also to get back to Bugara and start printing Bugara's notes. Moreover, the interaction is reinforced by the use of minor clauses by KAMINI in $(51,73)$ and CHAIRMAN in $(118)$ but also by abandoned clauses used by CHAIRMAN in $(115,123$, 136, 144). This has provided the text with its actual dialogic mode.

Regarding modality, it can be noticed that the presence of modal operator "can" in KAMINI's speech in $(11,14,31$, 47) aims at expressing probability, a possibility he has to secure the money for his country, on the one hand, and to get the loan and welcome the supervisors of the loan project, on the other. Similarly, the same modal operator is used in negative form in (10) to show the inopportuneness for the World Bank to control Bugara's currency. As regards CHAIRMAN, he also modalizes through verbal operators such as "may" in $(1,43)$, "would" in $(46,116)$. He utters them to show his own attitude and judgments related to the issue of loan and KAMINI's reaction. The second dimension of modality is modulation. The only example identified in the extract occurs in CHAIRMAN's speech. In fact, he uses the modal operator "must" in (123) to express the necessity of backing Bugara's national currency, which KAMINI does not want to understand.

Moreover, the writer makes use of high proportion of circumstantial adjuncts mainly, both in KAMINI's and CHAIRMAN's speech. Indeed, items which specifies location, eg: "of Bugara" (10), "in Bugara" $(48,56)$, "with their syphilitic spies" (52), "out to them" (72), "about rotten interest" (78), "in the first place" (108), "at this moment" (113), "to everybody" (139), "today" (145), etc, are used to "add experiential content to clauses by expressing some circumstances which refer to time, place, matter, etc. As for vocative adjuncts, one can point out that, in the excerpt, the phrase "your Excellency", which refers to KAMINI, the president is frequently used in CHAIRMAN's speech in $(1,19,22,27,36,43,58$, $61,71,77,106,112,119,122,136,143,146)$. This not only shows that there is an interaction between the two 
interactants, but it also reveals the degree of respect and fear, CHAIRMAN displays vis-à-vis KAMINI. Similar items used to address KAMINI include "my life president" in $(143,146)$. Textual adjuncts, which include conjunctive and continuity adjuncts occur in the text. As highlighted earlier, only two continuity adjuncts have been identified. Indeed, "ah" is used by KAMINI in (3), whereas in (124), he has used the adjunct "oh". These adjuncts are used "to introduce a clause and signal that a response to prior talk is about to be provided" (Eggins, 2004, p.160). Conjunctives abound in the speech of each interactant. As a matter of fact, conjunctive elements such as "so", "and", "or", "but", "when", "why", etc., are used to add textual meaning to the clauses and "they function to establish linking relations between one sentence and another"(Eggins, 2004, p.162). Moreover, mood adjuncts are also predominant in the text. CHAIRMAN uses such mood adjuncts to express probability [e.g.: "not exactly" (22)], intensification or minimization [eg: "just" (121), "simply" (23), "only" (46, 131),], certainty [eg: "I assure" (143)], presumption [eg: "even" (36)], usuality [eg: "never" (144)] about the different propositions conveyed. As for KAMINI, he has used mood adjunct "just" in (26, 93, 117,119, 128 131) and "only" (126), to express intensification and minimization and "still" $(60,70)$ to express usuality about the conditions surrounding the issue of loan.

In extract 2, as shown in the statistical analysis, full declarative mood is predominant in the speech of each interactant. For example, KAMINI uses declaratives in $(12,13,16,17,20,23,24,26,28,29,38,39,40,57,63,64,66$, $68,69,70,71,72,74,75,76,79,80,81,82,83,84,85,87,89,90,91,92,93,94,95,96,124,125,126,138,149)$, to name only a few of them. Similarly, AMBASSADOR uses declaratives in $(4,5,9,14,42,43,44,47,54,60,61,62,99$, $106,107,108,109,110,111,112,119,120,121,139,140,141,144,146,157)$. As for GUDRUM, he uses full declaratives in $(7,18,30,31,32,33,34,35,36)$. This implies that each interactant's speech mainly aims at giving information. In fact, the AMBASSADOR has come to inform KAMINI that some members of his cabinet have left. In order to get more clarifications regarding the conditions of their departure, polar interrogatives have been used by KAMINI in $(37,41,65,114,116,123)$ and wh- interrogatives in $(2,3,6,11,21,22,25,27,46,53,67,73,100,103,118,132,142$, 143 ) to request for more information regarding the circumstances surrounding their running away. The AMBASSADOR's role in this extract is simply to answer all the questions straight away, which accounts for her use of declarative mood and abandoned clauses in $(51,59,134,145,147)$. In addition, GUDRUM is a journalist who approves of any decisions taken by KAMINI; this shows how he has criticized these officials in his speech. Actually, the real dialogic mode of this passage is revealed not only through the use of elliptical Wh-interrogatives as pointed out earlier, but also the use of minor clauses by KAMINI in $(10,11,20,45,52,127,130,131,148)$ and AMBASSADOR in $(48,49,50)$. In this dialogue, both KAMINI and AMBASSABOR have played, interchangeably, the role of speaker and hearer; nevertheless, this overlaps with the role of questioner played by KAMINI and responder played by AMBASSADOR. Moreover, the text displays some instances of imperative mood, showing that "the text goes simply giving information, because the conveyed information has the potential to be packaged as goods and services" (Eggins, 2004, p.332). Actually, the peculiarity of this text is that these imperative mood-types are used by KAMINI, the president in clauses $(55,56,58,86,88,135,150,152,154,155)$. KAMINI has used them to give commands. Indeed, in clauses $(55,56,58,86,88)$, he orders the AMBASSADOR to see to the promotion of Seli Metatu after the departure of the others. Similarly, in (135), it is an instruction to AMBASSADOR to keep quiet when KAMINI is talking and in $(150,152,154,155)$ KAMINI commands AMBASSADOR to get into touch with the presidential Task Force Special to go to the four men's villages. Finally, there is a use of imperative mood by KAMINI in (113) and this expresses disgust vis-à-vis the four officials who run away.

Regarding the use of modality in the text, one can notice that modalization is distributed among the three characters. They are used to express the interactants' attitudes and judgments about the conditions under which some of his officials have run away. KAMINI modalizes in $(21,27,91,115,137)$, AMBASSADOR in $(60,134,145)$ and GUDRUM in $(30,31)$. It is important to mention that KAMINI uses "can" to say how likely members of his cabinet and some of his officials have betrayed him. As for GUDRUM, he uses "can" in (30) and "could" in (31) to confirm how likely AMBASSADOR will represent KAMINI's opinion when he is not present, on the one hand, and the possibility to help her, on the other. Regarding AMBASSADOR, she uses "may" in $(60,134)$ and "could" in $(145)$ to express her own opinion and her explanation on the issue being discussed. As far as modulation is concerned, it must be pointed out that both KAMINI and AMBASSADOR have used modulation. KAMINI modulates in $(90,93,98)$ whereas AMBASSADOR does so in $(14$, 49, 99, 107, 121, 157). This means that Ambassador modulates more than president KAMINI. Actually, this does not imply that she has instructed the president to do things for her, but, rather, she has expressed her obligation to execute the president's decisions.

Moreover, as noticed in text1, and pointed out in the previous session, this text displays various types of adjuncts namely circumstantial adjuncts, used mainly by KAMINI and AMBASSADOR. These elements indicate: (i) temporal or spatial location such as "immediately" in (14), "in appointment" in (20), "from our own Bugara University" in (41), "here" in (44), "for an hour or more" in (112, 121), (ii) manner such as "correctly" in (28), "carefully" in (104), "very carefully" in 
(107). Apart from circumstantial adjuncts, the text has also displayed an important number of vocative adjuncts used most specifically by Ambassador. Actually, vocative adjuncts such as "your (Gracious) Excellency" in $(1,5,14,42,54,60,99$, $106,119,134,139,144,157)$ shows the degree of respect Ambassador has for the president. On his turn KAMINI uses the adjunct "you, Madam Ambassador" in (20) and "Madam Ambassador" in (153) to address AMBASSADOR during their conversation. In addition, mood adjuncts are also used by the three interactants. GUDRUM uses "actually" in (18) and "of course" in (30) to express inclination and certainty. First, "actually" in (18), is used to persuade KAMINI that Seli Metatu is a young graduate who is very bright and second, "of course" in (30) is meant to assure KAMINI that AMBASSADOR is capable of writing the president's address. Similarly AMBASSADOR uses mood adjuncts in (42) to assure that Seli Metatu has got his doctorate degree from Bugara University. Conjunctive adjuncts are also used predominantly by Kamini to hang clauses together and relate them to the context of use. These elements are used "to express the logical meanings of elaboration, extension and enhancement" (Eggins, 2004, p. 162).

Actually, through the study of mood and modality, we can deduce the tenor variables of each text in terms of power, contact and affective involvement. As a matter of fact, in text1, imperative mood clauses are only used by KAMINI to order CHAIRMAN to do things. In addition, the use of vocatives such as "Your Excellency", "your gracious Excellency", "Dr Life president", etc. illustrates a situation where KAMINI has more power than CHAIRMAN as the use of vocatives is non-reciprocal. In addition, the organization of the interrogative mood clauses describes a situation where CHAIRMAN is obliged to answer all the questions put to him immediately. In the second text, conversation is organized in a similar way between KAMINI and AMBASSADOR. Indeed, there are predominantly cases of non-reciprocal vocatives such as "your Excellency" which are added to each explanation provided by AMBASSADOR. All the imperatives are produced by "life president" KAMINI to show that orders are given and KAMINI uses high modalisations and some instances of modulation more than AMBASSADOR. From the above analysis, we can deduce that the mood analysis in text1 reveals there is an unequal power between KAMINI and CHAIRMAN; the contact is frequent and the affective involvement is low. As for text 2, we notice that the power between the main interactants, KAMINI and AMBASSADOR, is unequal, the contact is frequent and the affective involvement is low.

From all the above analysis, a further linguistic appreciation of the findings has prompted us to deduce that $A$ Play of Giants is a satirical play in which the writer portrays the tyranny and dictatorship orchestrated by some African leaders. According to Jeyifo (2004, p.96), the play involves a rather extended, static tableau in which the "giants" of the title, KAMINI, GUNEMA, KASKO and TOBUM- each respectively serving as very thinly disguised representations of Idi Amin, Macias Nguema, Jean-Bedel Bokasa and Mobutu - talk about and parade themselves as incarnations of replete, fulfilled power. Through the study of mood and modality analyses in the two selected excerpts, one can understand how the writer has carried out a portrayal of one of the main protagonist of the play, i.e., KAMINI. In the first extract, we notice how KAMINI has used the various mood types to express his disapproval of the fact that some conditions must be met before the loan can be granted. Actually, KAMINI is portrayed as an illiterate who lacks basic knowledge in economics and finance. He takes all decisions without taking into account their consequences. This is illustrated through the whinterrogative mood in (24) and imperatives in $(25,26)$ : "What I care about condition. Agree to any condition. Just get the Ioan". Actually, in the context of the play, international financial institutions grant loans to some developing countries to finance development projects. Unfortunately, some African leaders like KAMINI use this money for their personal purposes. In addition, the theme of dictatorship and tyranny described in the play is well illustrated in the character of KAMINI. For example, in $(112,113,114,115,116)$, CHAIRMAN's attempt, through declarative mood, to explain why it is impossible to print Bugara notes has been interrupted by interrogative mood in $(117,118)$. This shows that apart from being a despot, KAMINI is a self-centered president who is not ready to receive any advice from others. He even decides to torture CHAIRMAN. This is a proof that as the president of Bugara, KAMINI is more concerned with his selfish interests. The well-being of his country does not matter. In addition, he has very little knowledge about diplomatic relations and he is a prototype of a corrupt leader. Similarly in text 2, bad governance is a political system put in place by KAMINI. As a matter of fact, in text 2, the information provided by AMBASSADOR in $(8,9)$ shows that KAMINI is a stubborn dictator. Fed up with supporting him, some of his collaborators have decided to run away. This has irritated him because the specialist of the presidential speech is among them. In (10), the use of minor clause "my speech" is another form of satire where Soyinka portrays the intellectual incapability of the president as the passage shows that he is not able to write his own speech and he has to hire somebody who will be doing the work for him. The hypocrisy of Bugara president is displayed when he is told that the minister of foreign affairs is among those who ran away. The use of various mood types from (63) to (85) illustrates how he wrongly accuses his minister, a strategy to avoid disclosing what he is used to doing with the money of the country. Finally, the use of imperative clauses in $(150,152,154,155)$ shows that KAMINI is a demagogue and a tyrant who always pretends to preserve the interest of his country.

On the whole, this paper has inquired into the language of Wole Soyinka's A Play of Giants. The theory of mood 
and interpersonal meaning has been accounted for in terms of definitions and clarifications. The practical analysis has shown that various mood types have been identified in the interactants' speech and their study has impacted the understanding of style and meaning of the author. The interpersonal meaning has proved conclusive. All in all, through the portrayal of KAMINI, the writer has arrowed some socio-political cankers, vices and follies of some African leaders. More importantly, the writer is raising his readers' awareness on the fact that, some African leaders are responsible the underdevelopment of Africa as their mode of management does nothing but holds back the development of the continent.

\section{References}

Amoussou, C. Y. (2014). Discourse Tenor, Context and Character in the Lawyer's Monster Parable (Petals of Blood); Particip'action, 6 (1), $147-170$.

Amoussou, C. Y. (2015). Mood, Interpersonal and Ideological Meaning Patterns in the 'Abiku' Poems (J. P. Clark, W. Soyinka). International Journal of Language and Linguistics. 2 (3), 129-138.

Bloor, T., \& Bloor, M. (2004). The Functional Analysis of English: a Hallidayan Approach (2nd ed.). London: Hodder Education.

Eggins, S. (1994). An Introduction to Systemic Functional Linguistics. London: Pinter Publishers.

Fowler, R. (1986). Linguistic Criticism. Oxford: Oxford University Press.

Halliday, M. A. K. (1973). Explorations in the Functions of Language. London: Edward Arnold.

Halliday, M. A. K. (1978). Language as a Social- Semiotic: The Social Interpretation of Language and Meaning. London: Edward Arnold. Halliday, M. A. K. (1985). Introduction to Functional Grammar. London: Edward Arnold.

Halliday, M. A. K. (2002). Linguistic Studies of Text and Discourse. Collected Works of Michael Halliday, Vol. 2. Edited by J. J. Webster. London and New York: Continuum.

Halliday, M. A. K., \& Hasan, R. (1976). Cohesion in English. London: Longman Group.

Halliday, M. A. K., \& Hasan, R. (1985). Language, Context, and Text: Aspects of Language in a Social-semiotic Perspective. Oxford: Oxford University Press.

Halliday, M. A. K., \& Matthiessen, C. (2004). An Introduction to functional grammar (3rd ed.). London: Edward Arnold.

Jeyifo, B. (2004). Wole Soyinka: Politics, Poetics and Postcolonialism. Cambrige: Cambridge University Press

Hasan, R. (1985/1989). Linguistics, Language and Verbal Art. Oxford: Oxford University Press.

Koussouhon, A. L., \& Dossoumou, A. M. (2014). Lexico-Grammatical Analysis of Yellow-Yellow by Kaine Agary with a Focus on Experiential and Textual Meanings. Mediterranean Journal of Social Sciences, 5(23), 2430-2436. http://dx.doi.org/10.5901/mjss. 2014.v5n23p2430

Koutchadé, I. S. (2015). Discourse Analysis of General Muhammadu Buhari's Official Acceptance Speech: A Systemic Functional Perspective. International Journal of English Linguistics, 5(5), 24-36. http://dx.doi.org/10.5539/ijel.v5n5p24.

Ngara, E. (1982). Stylistic Criticism and the African Novel. London: Heinemann

Simpson, P. (2004). Stylistics: A Resource Book for Students. London: Routledge.

Appendix: Mood, modality and adjunct- types identification of the texts

The following keys have been used to carry out this identification:

Keys

S= Subject; F= Finite; $\quad F n=$ negative; Fms= Modalized; $\quad F m l=$ modulated; $\quad P=$ Predicator; $P m s=$ modalized predicator; $\quad$ Pml= modulated predicator; $\quad F / P=F u s e d$ Finite and predicator; $C=$ complement ; $\quad \mathrm{Ca}=$ attributive complement; $\quad \mathrm{A}=\mathrm{Adjunct} ; \quad \mathrm{Ac}=$ circumstantial adjunct; $A m=$ mood adjunct; $A 0=$ Comment adjunct; $A p=$ polarity adjunct; $A v=$ vocative adjunct; $A j=$ conjunctive adjunct; At= continuity adjunct; Wh= Wh-element; Wh/S Wh/C Wh/Ac fused Wh-element, mn=minor clause;

\section{Text 1}

[CHAIRMAN]: 1 May (Fms) I (S) come in (P) your Excellency (Av)?

[KAMINI]: 2. Who (Wh/S)? 3. Ah (At) come in (P) 4.come in (P) 5. Why (Wh/Ac) you (S) take (F/P) so long

(Ac) Mr Chairman (Av)? 6. You (S) excuse (F/P) me (C) 7. While (Aj) I (S) take (F/P) some business (C) 8. Is (F) my Chairman (C) of Bugara Central Bank (AC)? 9. When (Aj) I (S) travel (F/P), 10. I (S) take (F/P) Bank (C) of Bugara (Ac) with me(AC) 11. Then (Aj) nobody $(\mathrm{S})$ can $(\mathrm{Fms})$ steal $(\mathrm{P})$ money $(\mathrm{C})$ behind Kamini's back (Ac). 12. Too many Kondo(S) wearing (P) European coast and tie (C) 13. And(Aj) forging $(P)$ signature(S) of this and that bank manager (Ac). 14. When (Aj) Kamini not home (Ac) only chairman (S) can (Fms) sign $(P)$ cheque $(C)$ 15. And (Aj) he $(S)$ here with Kamini (Ac).

[KASCO] : 16-C'(S) est (F) sage (Ca), mon vieux(Av).

[KAMINI] : 17. So (Aj) what (Wh/S) happen (F/P)? 18. How much (Wh/C) loan (C) they (S) give (F/P) us (C)?

[CHAIRMAN]: 19. Your Excellency (Av), it(S) was ( $\mathrm{F}$ ) a difficult (Ca) meeting (C). 20. The world Bank (S) was not (Fn) very cooperative (Ca)

[KAMINI]: 21. They (S) don't (Fn) give (P) loan (C)?

[CHAIRMAN]: 22. Not exactly (Am), Your Excellency (Av) 23. They (S) simply (Am) insisted on (F/P) certain conditions... (C). 
[KAMINI]: 24. What (Wh/C ) I (S) care (F/P) about conditions $(\mathrm{Ac})$ ? 25. Agree $(\mathrm{P})$ to any conditions $(\mathrm{Ac})$ 26. Just $(\mathrm{Aj})$ get $(\mathrm{P})$ the loan (C).

[CHAIRMAN]: 27. It (S) is not $(\mathrm{Fn})$ quite $(\mathrm{Ca})$ as easy as $(\mathrm{Aj})$ all that $(\mathrm{C})$ your Excellency $(\mathrm{Av})$. 28. They $(\mathrm{S})$ want $(\mathrm{F} / \mathrm{P})[[$ to mortgage $(\mathrm{P})$ Bugara body and soul (C)...]]

[KAMINI]: 29. I (S) say (F/P) what(C ) 30. I (S) care (F/P) about body and soul (Ac). 31. If (Aj) they (S) can (Fms) loan (P) Bugara (C) the two hundred million dollars $(C)$ 32. I (S) give (F/P) them $(C)$ body and soul $(C)$. 33. Go back $(P)$ 34. And $(A j)$ agree $(P)$ to any condition (AC). 35. they (S) want (F/P).

[CHAIRMAN]:36.There $(\mathrm{S})$ is $(\mathrm{F})$ more $(\mathrm{C})$ to it $(\mathrm{Ac})$ your Excellency $(\mathrm{Av}) .37$ They $(\mathrm{S})$ don't $(\mathrm{Fn})$ even $(\mathrm{Am})$ want $(\mathrm{P})[[\mathrm{to}$ hand over $(\mathrm{P})$ the money $(\mathrm{C})$ directly $(\mathrm{AC})$ ]]. 38. In fact $(\mathrm{Aj})$, the board $(\mathrm{S})$ dismissed $(\mathrm{F} / \mathrm{P})$ that request $(\mathrm{C})$ outright $(\mathrm{Ac}) .39$. There $(\mathrm{S})$ was $(\mathrm{F})$ no discussion (C).

[KAMINI]: 40. What $(\mathrm{Wh} / \mathrm{C})$ they $(\mathrm{S})$ mean $(\mathrm{F} / \mathrm{P})$ by that $(\mathrm{Ac})$ ? 41. You $(\mathrm{S})$ not tell $(\mathrm{F} / \mathrm{P})$ them $(\mathrm{C})$ 42. Bank of Bugara $(\mathrm{S})$ is $(\mathrm{F})$ here with president in person $(\mathrm{Ac})$ ?

[CHAIRMAN]: 43. Your Excellency (S) may (Fms) rest assured (Ca) 44 that (Aj) I (S) explained (F/P) the position (S) very thoroughly (Ac). 45. But (Aj) their decision (S) is (F) 46 that (Aj) they (S) would (Fms) only (Am) fund (P) specific projects (C) with the loan (Ac).

[KAMINI]: 47. So (Aj) they $(\mathrm{S})$ can (Fms) come $(P)$ 48. and $(A j)$ send $(P)$ their stinking spies $(C)$ into Bugara $(A c)$ 49. Saying $(P)$ 50. they $(\mathrm{S})$ come $(P)$ [ $[$ to supervise $(P)$ loan project $(C)$ ?] $]$ 51. No deal $(\mathrm{mn})$ 52. Kamini(S) wise $(\mathrm{Ca})$ to their game $(A c)$ of infiltrating $(P)$ third world country $(C)$ with their syphilitic spies (Ac). 53. Go (P) back (C) 54. And (Aj) tell (P) them (C). 55. Either (Aj) they (S) loan (F/P) ready cash $(\mathrm{C})$ direct $(\mathrm{AC})$. 56. Or $(\mathrm{Aj}) \mathrm{I}(\mathrm{S})$ take over $(\mathrm{F} / \mathrm{P})$ all remaining foreign business $(\mathrm{C})$ in Buguara $(\mathrm{Ac})$. 57. Any member country of World Bank with business $(\mathrm{C})$ in Bugara $(\mathrm{AC})$, we $(\mathrm{S})$ nationalise (F/P).

[CHAIRMAN]: 58. Your Excellency $(A v)$ I $(S)$ did $(F)$ outline $(P)$ that possibility $(C)$ to them $(A c)$ 59. I $(S)$ left $(F / P)$ them (C) in no uncertainty of such as consequence (Ac)

[KAMINI]: 60. And (Aj) still (Am) they (S) say (F/P) no (C)?

[CHAIRMAN]: 61. I (S) am (F) afraid (Ca) so (Aj) Excellency (Av)

[GUDRUM]: 62. It (S) is (F) a plot (C) my Life President (Av). 63. It (S) is (F) part(C) of their deliberate economic sabotage (Ac)

[KAMINI]: 64. I (S) know (F/P). 65. It(S) is (F) dirty (Ca) capitalist plot (C) all over (Ac). 66. World Bank (S) belongs (F/P) to everybody $(A c)$. 67. Why $(\mathrm{Wh} / \mathrm{Ac})$ they $(\mathrm{S})$ are $(\mathrm{F})$ discriminating $(\mathrm{P})$ against Bugara alone $(\mathrm{Ac})$ ? 68. Why $(\mathrm{Wh} / \mathrm{AC})$ they $(\mathrm{S})$ give $(\mathrm{F} / \mathrm{P})$ Hazena loan (C)? 69. You (S) tell (P) me (C). 70. Hazena (S) still (Aj) owns (F/P) them (C) more money (C) than (Aj) Bugara (C) not so?

[CHAIRMAN]: 71. That (S) is (F) a fact (C) your Excellency (Av). 72. I (S) pointed (F/P) it (C) out to them (AC).

[KAMINI]: 73. Aha! (mn) 74.So (Aj) what (Wh/C) they $(\mathrm{S})$ say (F/P)? 75. What (Wh/C) they (S) say (F/P) to that enh $(\mathrm{Ac})$ ?

[CHAIRMAN]:76. They $(\mathrm{S})$ replied (F/P) 77. That $(\mathrm{Aj})$ Hazena $(\mathrm{S})$ had $(\mathrm{F})$ been $(\mathrm{F})$ paying $(\mathrm{P})$ interest $(\mathrm{C})$ regularly $(\mathrm{Ac})$ your Excellency (Av).

[KAMINI]: 78. What (Wh/C) I (S) care (F/P) about rotten interest (Ac)? 79. Bugara (S) promised (F/P) [[to pay (P) everything (C) all at once $(A C)$, in five years $(A C)]]$. 80. So $(A j)$ what $(W h / C)$ I $(S)$ care $(F / P)$ about stupid interest $(A c)$ enh? 81 . Taking $(P)$ interest $(C)$ 82. taking interest $(C)$ 83. and $(A j)$ finishing up(P) all Bugara foreign exchange $(C)$.

[GUDRUM]: 84. Bugara (S) has (F) more than (Aj) contributed $(\mathrm{P})$ its quota $(\mathrm{C})$ to the World Bank $(\mathrm{AC})$. 85. That $(\mathrm{S})$ is $(\mathrm{F})$ a fact $(\mathrm{C})$ your Excellency (Av). 86. When (Aj) the economic (S) was (F) buoyant (Ca). 87. Bugara (S) never (Am) missed (F/P) a payment (C).

[KAMINI]: 88. Is (F) what (C) am (F) saying (P) 89. And (Aj) is (F) all discrimination and dirty imperialist plot (C). 90. I (S) make (F/P) complaint $(C)$ to Secretary - General $(A c)$ today $(A c)$ 91.and (Aj) raise (F/P) matter $(C)$ in General - assembly (Ac). 92. Let World Bank $(\mathrm{S})$ tell $(\mathrm{P})$ us $(\mathrm{C})$ once for all $(\mathrm{Ac})$. 93. If $(\mathrm{Aj})$ it $(\mathrm{S})$ is $(\mathrm{F})$ just $(\mathrm{Am})$ for rich countries and neo- colonial bastards like Hazena (Ac). 94. Or $(A j)$ it $(S)$ belongs (F/P) to third world countries $(A C)$. 95. Who (S) need (F/P) loan (C) 96. As for you(Aj), Get back $(P)$ to Bugara right away(Ac) 97. and(Aj) start(F/P) [[ printing (P) more Bugara bank notes (C)]]. 98. I (S) show (F/P) the bastards (C) 99. At least (Aj) they (S) can't (Fnms) control (P) Bugara sovereign currency (C).

[CHAIRMAN]: 100. I (S) beg (F/P) your pardon (C) Dr. Life President (Av)?

[KAMINI]: 101. I (S) said (F/P) 102. go back (P) 103. and (Aj) get (P) cracking(Ca) with government mint $(\mathrm{Ac})$ 104. When $(\mathrm{Aj})$ I $(\mathrm{S})$ return (F/P) 105. I (S) want (F/P) [[to see (P) brand-new currency notes $(C)$ in circulation $(A C) / /$ not hearing $(P)$ all this grabble of shortage of money and so one and so forth $(C)]]$.

[CHAIRMAN]: 106. But (Aj) your Excellency (Av) 107.that (S)'s (F) 108. why (Aj) we (S) came (F/P) [[ to seek (P) this loan(C) in the first place $(A C)]] .109$ Now $(A C)$ that $(A j)$ we $(S)$ haven't $(F n)$ got $(P)$ it $(C)$ 110. There $(S)$ is $(F)$ nothing $(C)$ [ $[$ to back $(P)$ the new currency with (C)]].

[KAMINI]: 111. What $(\mathrm{Wh} / \mathrm{C})$ the man $(\mathrm{S})$ talking $(\mathrm{P})$ about $(\mathrm{Ac})$ ? 104 you $(\mathrm{S})$ short of $(\mathrm{F} / \mathrm{P})$ good currency paper $(\mathrm{C})$ at government mint (AC)?

[CHAIRMAN]: 112. I (S)'m (F) trying (P) //to explain (P), Your Excellency (Av)113. Even(Aj) now(Ac), at this moment (Ac), our national currency $(S)$ is not $(F n)$ worth its size in toilet paper $(A C)$. 114. If $(A j)$ we $(S)$ now $(A C)$ go ahead $(F / P)$ 115. and (Aj) print (F/P) more (C) 116. it (S) would (Fms)...

[KAMINI]: 117 What $(\mathrm{Wh} / \mathrm{C})(\mathrm{mn})$ ? 118. What $(\mathrm{Wh} / \mathrm{C})$ you $(\mathrm{S})$ say $(\mathrm{F} / \mathrm{P})$ just(Am) now $(\mathrm{Ac})$ ?

[CHAIRMAN]: 119. Your Excellency? (Av) (mn)

[KAMINI]: 120. I (S) say (F/P) 121. what (Wh/C) you(S) talking (P) just (Am) now about Bugara currency (Ac)?

[CHAIRMAN]: 122. Just(Am) that (Aj) all currency (S) needs (F/P) backing (Ca) your Excellency (Av). 122. It (S) must (Fml) be (P)....

[KAMINI]: 123. No, (Ap) you (S) said (F/P) Bugara currency only(Am) Worth(Ca) something(C) this and (Aj) that (C).

[CHAIRMAN]: 124. Oh (At) I (S) was (F) trying $(\mathrm{P})[[$ to explain $(\mathrm{P})]$ ] 125. that $(\mathrm{Aj})$ any paper money $(\mathrm{S})$ is $(\mathrm{F})$ only $(\mathrm{Am})$ worth $(\mathrm{Ca})$ what... 
(C)

[KAMINI]: 126. You (S) saying (P) Bugara currency (C) only(Am) worth ship paper (Ca)? 127 is $(\mathrm{F})$ that $(\mathrm{S})$ 128. What $(\mathrm{Wh} / \mathrm{C})$ I (S) hear (F/P) you (C) [[say (P)] just(Am) now (Ac)? 129 Is (F) that (S) 130. what (C) I (S) hear (F/P) you (C) say (P) just (Am)now (Ac)?

[CHAIRMAN]: 131. Your Excellency (Av) I (S) was (F) only (Am) trying (P) [[to illustrate (P)...]]

[KAMINI]:132. You(S) see (F/P) 133. is (F) this kind of traitor (C) 134. I (S) have (F) in charge of Bugara central Bank (Ac). 135. This syphilitic bastard(S) talking(P) worse than imperialist propaganda (AC).

[CHAIRMAN]: 136.Your Excellency.... (Av) (mn).

[KAMINI]: 137. Is (F) no wonder(Ca)138. Bugara (S) getting broke (P) all the time (Ac). 139. When(Aj) this kind of chairman(S) insulting(P) Bugara national currency $(C)$ 140.calling (P)it (C) shit paper(Ca ) to everybody $(A c)$ 140. this the kind of person $(S)$ going $(P)$ to important meeting of world Bank (AC) [[to ask (P) for loan (C)]] 141. You(S) think (F/P) world Bank (S) give (F/P) Bugara loan (C) 142. when $(\mathrm{Wh} / \mathrm{AC})$ you calling $(\mathrm{P})$ national currency shit paper $(\mathrm{C})$ ?

[CHAIRMAN]: 143. My life president (Av), I assure (Am) Your Excellency (Av) 144.I (S) never(Am)... (mn)

[KAMINI]: 145. Today (AC) I (S) make (F/P) you( C) [[eat(F/P) good old Bugara shit (C)]].

[CHAIRMAN]: 146 Your Excellency(Av) my Life President... (Av)

[KAMINI]: 147. Taking $(\mathrm{P})$ around with me(Ac) 148. Sneaking( $\mathrm{P})$ traitor(C) left and right( $(\mathrm{Ac})$ 149.talking $(\mathrm{P}) \operatorname{bad}(\mathrm{Ca})$ about Bugara $(\mathrm{Ac})$. 150. Today (Ac) I (S) make (F/P) you (C) [[ smell (P) your mother's cunt... (C)]].

\section{Text 2}

[AMBASSADOR]: 1.Your Gracious Excellency... (Av)

[KAMINI]: 2. What (Wh/C) is (F) it (S)? 3. why (Wh/Ac) do (F) you(S) continue(F/P) [ [to disturb (P)?]]

[AMBASSADOR]: 4. They (S) 've (F) gone (P), your Excellency (Av). 5. The rest of the delegation (C), they $(S)^{\prime} v e(F)$ gone $(P)$.

[KAMINI]: 6. What (Wh/C) did (F) you (S) say (P)?

[GUDRUM]:7. Some more traitors $(\mathrm{S})$ have $(\mathrm{F})$ shown $(\mathrm{P})$ their true faces $(\mathrm{C})$, your Excellency (Av).

[AMBASSADOR]: 8. They (S) left (F/P) straight (Ca) after the working session (Ac) of the Foreign Minister's committee (Ac). 9.The foreign Affairs Minister, his secretary, the two specialists on Palestinian and south African problems- Dr. wamue and Mrs Olanga and that new ...(C).

[KAMINI]:10. My speech (mn)! 11. What (Wh/S) happen (F/P) to speech (C) 12. he (S) prepares (F/P) for me (C) [ito address (P) General Assembly tomorrow (C)]]? 13. He (S) is(F) supposed(P) [[to read (F/P) it(C) to me (Ac) over lunch (Ac)]].

[AMBASSADOR]: 14. I (S) shall (F) assign (P) it (C) immediately (Ac) to the third secretary (Ac) your Gracious Excellency (Av).

[KAMINI]: 15. The third secretary (C) (mn). 16. the third secretary (C) [[to write (P) address of Bugara's life president (C)]] 17. Which (C) he (S) makes (F/P) to united Nations (C)?

[GUDRUM]:18. Actually (Am) he (S) is ( $\mathrm{F}$ ) very bright (Ca), Dr. President (Av), a young gradutate (C) but (Aj) very bright $(\mathrm{Ca})$.

[KAMINI]:19. The third secretary (mn)! 20. you, Madame Ambassador (Av), you (S) have (F) been (P) mistake (C) in appointment (Ac). 21. Why (wh/Ac) can (Fms) you (S) not write (P) the address (C)? 22. Why (Wh/AC)?. 23. Because (Aj) you (S) are (F) ignorant (Ca)! 24. I (S) have no (Fn) expert (C) 25. why (Wh/Ac) are (F) you (S) Ambassador (C) 26. if (Aj) you (S) are not (Fn) expert (C)? 27. Why $($ wh/ $\mathrm{Ac})$ can $(\mathrm{Fms})$ you $(\mathrm{S})$ not represent $(\mathrm{P})$ my opinion (C) 28. and (Aj) put $(\mathrm{P})$ it $(\mathrm{C})$ correctly $(\mathrm{Ac})$ 29. if $(\mathrm{Aj})$ I (S) am not (Fn) here (AC).

[GUDRUM] 30. Of course (Am) she (S) can (Fms) your Excellency (Av), 31. I (S) could (Fms) lend (P) a hand (C) too (Aj) 32. if (Aj) your Excellency (Av) wishes (F/P) 33. but (Aj) this young graduate $(S)$ had $(F)$ studied $(P)$ all the life president's speeches $(C)$ at the university (Ac). 34. He (S) did (F/P) his doctorate(C) on the very subject (AC). 35. I (S) have (F) read (P) some of the briefings (C) 36. he (S) prepared (F/P) for the delegation (C).

[KAMINI]: 37. Is(F) that(S) so(Ca)? 38. I know (Am) that (Aj) my political philosophy $(\mathrm{S})$ and $(\mathrm{Aj})$ so on $(\mathrm{S})$ are $(\mathrm{F})$ studied $(\mathrm{P})$ in university (Ac). 39. but (Aj) I (S) did not (Fn) know $(P)$ 40. somebody $(S)$ has $(F)$ been getting $(P)$ doctorate degree $(C)$ from them $(\mathrm{Ac}) .41$. Does $(\mathrm{F})$ he $(\mathrm{S})$ get $(\mathrm{P})$ his Doctorate $(\mathrm{C})$ from our own Bugara University $(\mathrm{Ac})$ ?

[AMBASSADOR]: 42. Certainly (Am) your Excellency (Av) 43. and (Aj) he (S) has (S) given (P) many public lectures on the subject (C) 44. since (Aj) he (S) tool up (F/P) position (C) here (AC).

[KAMINI]: 45 . Very good, very good ( $\mathrm{mn})$ 46. but (Aj) where (Wh/Ac) is (F) the first secretary $(\mathrm{S})$ ?

[AMBASSADOR]:47. That position (S) has (F) been (P) vacant (Ca) for two years (Ac) your Excellency (Av), 48. same thing for second secretary (mn). 49. If (Aj) your Excellency (S) will (Fml) be (P) kind enough (Ca) [[to recall (P) several memos (C)]] 50.I (S) sent (F/P) to the Ministry of foreign affairs on the subject (C) 51 . Copied(P) to your Excellency (Ac) ...

[KAMINI]: 52. All right (mn) 53. What (Wh/C) is (F) the young man's name (S)?

[AMBASSADOR]: 54. Seli Metatu (S), your Excellency (Av)

[KAMINI]: 55. Promote $(P)$ him first secretary (C) 56. and (Aj) tell $(P)$ him [[to get on $(P)$ with my speech (Ac)]]. 57. still (Am) I (S) don't $(F n)$ like $(P)$ idea $(C)$ of third secretary $(A C)$ [ [writing $(P)$ speech(C) for a life president $(A C)]]$. 58. Promote (P) him (C) today (AC)

[AMBASSADOR]: 59. But (Aj) if (Aj) er... 60. If (Aj) I (S) may (Fms) make (P) bold (C) [ [to remind (P) Your Excellency (Ac)]] 61. the reason $(S)[[w h y$ the post of First and second secretaries, plus that of commercial attache $(S)$ have $(F)$ been $(P)$ vacant $(C a)]](S)$ is $(F)$ 62. that (At) well (At), according to the foreign affairs Minister(Ac), there $(\mathrm{S})$ are not $(\mathrm{Fn})$ Funds $(\mathrm{C})[$ to pay $(\mathrm{P})$ anyone $(\mathrm{C})$ in those grades (AC)]].

[KAMINI]: 63. I (S) remember (F/P) very well (Ca). 64. I (S) do not (Fn) forget (P) 65. And (Aj) is (Fn) that (S) not the same minister (C) 
66. Who $(S)$ has $(F)$ now $(A c)$ run away $(P)$ in the middle of his international mission $(A c)$ ? 67. Why $(W h / A c)$ do $(F)$ they $(S)$ all $(A j)$ run away $(P)$ ? 68. Because (Aj) they (S) steal (F/P) Bugara money (C), 69. that (S)'s (F) why (C). 70. They (S) smuggle (F/P) goods (C) 71. and $(A j)$ do $(F / P)$ black market $(C)$, [[ruining $(P)$ Bugara currency $(C)]]$ 72. you $(S)$ tell $(P)$ me $(C)$, [ [why that traitor, the one who $(S)$ calls $(F / P)$ himself professor $(C)]](C)$ 73. Why $(W h / A C)$ he $(S)$ run away $(P)$ [iinstead of $(A j)$ leading $(P)$ my team of delegation $(C)$ to this meeting here $(A C)]$ ]. 74. He (S) embezzles (F/P) money (C) 75. and (Aj) he (S) suspects (F/P) 76.that (Aj) Kamini (S) find out (F/P)] (C) 77. He knows (Am) I (S) want (F/P) [[to disgrace $(P)$ him $(C)$ before his international friends at the United National Assembly (Ac)]], a common thief like that $(C)$. 78. With all his grey hairs $(A C)$ he $(S)$ is $(F)$ so shameless (Ca) 79. So (Aj) everybody (S) thinking (P) him a great scholarship man $(C)$ a brilliant man and so on and so forth $(C)$ 80. A brilliant man (S) to be (Fn) embezzling (P) money (C) 81. and (Aj) running away $(P)$. 82. Thank $(P)$ you $(C)$ very much for brilliance $(A C)$. 83. I (S) take (F/P) stupid man any day (C). 84. I(S) promote $(P)$ that young man $(C)$, today $(A C)$. 85. When $(A j)$ he $(S)$ come back $(F / P)$ to Bugara $(A c)$, 86. See $(P)$ that $(C)$ 87. he $(S)$ go $(F / P)$ to university $(A C)$ 88. and $(A j)$ make $(P)$ him professor $(C)$. 89. But if (Aj) he (S) try (F/P) [[to be (P) brilliant (Ca) like Kiwana (C)]], 90.he (S) will $(F m l)$ smell $(P)$ his mother's cunt $(C)$ 91. before $(A j)$ he $(S)$ can (Fms) run away $(P)$. 92. Now $(A C)$ I $(S)$ find (F/P)new Foreign Minister (C) 93. Who $(\mathrm{S})$ will $(\mathrm{Fml})$ find $(\mathrm{P})$ money $(\mathrm{C})$ 94. and $(\mathrm{Aj})$ pay $(\mathrm{P})$ salaries $(\mathrm{C})$ 95. instead of $(\mathrm{Aj})$ running away $(\mathrm{P})$ with Bugara money (Ac). 96. Perhaps (Am) I (S) make (F/P) you the Foreign Minister (C). 97. You (S) are (F) useless (Ca) as (Aj) Ambassador (C) 98. When (Aj) you (S) cannot (Fnms) write (P) my speech (C) in emergency (Ac).

[AMBASSADOR]:99. Your Gracious(Ca) Excellency's orders (S) will (Fml) be carried out (P)

[KAMINI]: 100. How (Wh/Ac) did (F) they $(\mathrm{S})$ get away $(\mathrm{P})$ ? 101. I (S) want (F/P) the names $(\mathrm{C})$ of my Task Force Specials (Ac) 102. who $(S)$ are $(F)$ watching $(P)$ their movement $(C)$ hand and foot $(C a)$ 103. How $($ Wh/Ac) did $(F)$ all of them $(S)$ get away $(P)[[$ without $(A j)$ being followed $(P)$ ?] ] 104. I (S) tell (F/P) them (C) [[to watch $(P)$ carefully $(A C)]]$ 105. even when $(A j)$ they $(S)$ go $(F / P)$ to toilet $(A c)[[t o$ shit $(P)]]$.

[AMBASSADOR]:106. I (S) have (F) already (Aj) set up (P) an enquiry (C) your Excellency (Av). 107. They (S) must (Fml) have planned $(P)$ it $(C)$ very carefully $(A C)$. 108. They $(S)$ pretended $(F / P)$ 109. They $(S)$ were still $(A m)$ holding $(P)$ their meeting $(C)$ in the committee room $(A c)$ 110. But (Aj) in fact $(A j)$ they $(S)$ had $(F)$ all $(A j)$ escaped $(P)$ through lavatory window $(A c)$. 111. It $(S)$ opened $(F / P)$ into a passage $(A c)$ used $(P)$ only $(A j)$ by the cleaners in the building $(A c)$. 112. The presidential Task Force Guards $(S)$ kept $(F)$ waiting $(P)$ at the door (Ac) for over an hour (Ac) before...(AC)

[KAMINI]:113. What fools (Wh/At)! 114. Did (F) they (S) not notice $(P)$ 115. that (Aj) they $(S)$ can (Fms) no longer $(A c)$ hear $(P)$ anything (C)? 116. Did (F) they (S) think (P) 117. the delegation (S) was (F) Sleeping (P) 118. Or (Aj) What (Wh/S) ?

[AMBASSADOR]:119. Your Gracious Excellency (Av), they $(\mathrm{S})$ were $(\mathrm{F})$ clever $(\mathrm{Ca})$ 120. They $(\mathrm{S})$ left on (F/P) a tape recorder of conversation (C)121. which (S) must (Fml) have (F) kept running $(P)$ for an hour or more $(A C)$.

[KAMINI]:122. You(S) see (F/P).123. Is (F) It (S) not a disgrace $(C)$ ? 124. A whole minister of state, he $(S)$ is $(F)$ playing (P) tricks (C) like 007 James Bond $(A c)[[$ in order to run away $(P)$ with national Funds $(A c)]]$.125. That $(S)$ is $(F)$ 126. the kind of minister $(S)$ left $(P)$ in Bugara (Ac). 127. James Bond $(\mathrm{mn})$.128. That $(\mathrm{S})$ is $(\mathrm{F})$ what ( result(C) from imperialism and neo-colonialism and the culture (Ac)129.they (S)teach (F/P) our people (C) 130..Syphilitic culture (mn) .131.Mental syphilis (mn) .132. How (Wh/ Ac) you (S)explain (P) a thing $(C)$ like This $(A c)$ ?133. An educated man, a cabinet minister $(S)$ playing $(P)$ like James Bond $(C)$ in the United Nations (Ac) .

[AMBASSADOR]:134.Your Excellency (Av), if (Aj) I (S) may... (Fms)

[KAMINI]:135. Don't (Fn) interrupt (P) .136. You (S) are (F) not a good Ambassador (C) 137. or (Aj) this (S) would not (Fnms) happen $(P)$ under your nose $(A c)$.138. Have $(F)$ you $(S)$ telexed $(P)$ Bugara $(C)$ for the Tast Force $(A C)$ [ [to go $(P)$ to these people's villages $(\mathrm{AC})]]$ ?

[AMBASSADOR]:139. Your Gracious Excellency (Av) , I (S) was (F) [[ about to suggest (P) ]] (C) 140. That (Aj) I (S) run (F/P) over to a friend embassy (Ac)141. and (Aj) use (F/P) their telex (C) .

[KAMINI]:142. Why $(\mathrm{Wh} / \mathrm{S})$ a friend embassy $(\mathrm{S})$ ? 143. Why not $(\mathrm{Wh} / \mathrm{Ac})$ our own telex $(\mathrm{S})$ ?

[AMBASSADOR]:144. It (S) was (F) cot off (P) months ago (Ac), your Excellency (Av) .145. we (S) ...could not (Fnms) pay (P) ...146. We (S) had (F) no funds (C)[[ to settle (P) our bills (C),]] 147. The foreign Minister (S) was (F) aware (Ca) of ...(Ac)

[KAMINI]:148. The foreign Minister (mn)! 149. I (S) do not (Fn) want $(P)$ [[to hear $(P)$ the name(C) of ...those traitors any of them $(A c)$ .150. Just $(A m)$ get $(P)$ a message $(C)$ 151. any way $(A j)$ you(S) lie $(F / P)$ to my presidential Task Force Specials $(A c)$ 152. and $(A j)$ dispatch $(P)$ them $(C)$ to their villages $(A c)$.153. you $(S)$ have $(F)$ already $(A j)$ lost $(P)$ precious time $(C)$ Madame Ambassador (Av) .154. and $(A j)$ report $(P)$ the matter $(C)$ to The Secretary General of the United Nations $(A C)$.155. Let him $(S)$ know $(P)$ 156.what bad things $(C)$ his people $(S)$ have $(F)$ done $(P)$ to me $(C)$.

[AMBASSADOR]:157. I (S) will (Fml) attend (P) to it (Ac) your Excellency(Av) . 